\title{
Seven Deadly Sins: Culture's Effect on Scholarly Editing and Publishing
}

\author{
Lilia Raitskaya ${ }^{1}$, Elena Tikhonova ${ }^{2,3}$ \\ ${ }^{1}$ Moscow State Institute of International Relations (MGIMO University) \\ ${ }^{2}$ National Research University Higher School of Economics \\ ${ }^{3}$ Peoples' Friendship University of Russia (RUDN University)
}

Correspondence concerning this article should be addressed to Elena Tikhonova, National Research University Higher School of Economics, 11 Pokrovsky Bulvar, Pokrovka Complex, room S313, Moscow, 109028, Russian Federation.E-mail: etihonova@hse.ru

\begin{abstract}
The opinion piece aims to draw readers' attention to the effects cultures other than Englishrelated ones exert on the processes of scholarly editing and publishing. Non-Anglophone writers with little academic English skills or a weak command of English tend to face deskrejections or very difficult and time-consuming rounds of edits and revisions. Second-language researchers often are biased toward national schools of thought with the most prominent international research ignored. Such authors are unaware of the recent developments in their field on a global scale and are sometimes prone to misunderstanding scientific and academic genres in the internationally accepted mode. Non-Anglophone writers are also inclined toward native-language patterns of thought and, consequently, rhetorical schemas different from English. Such second-language researchers may have their specific understanding of ethics and criticism, responding to the latter in an unexpectedly harsh way. This combination of factors can lead to unoriginal, vague, unimportant, and unacceptable submissions to international journals, resulting in failures to disseminate their research globally. The authors share their approaches to curbing unpleasant and inefficient experiences for second-language contributors, editors, and reviewers.
\end{abstract}

Keywords: high-ranking journal, scholarly editing, rhetoric schema, international journal, academic genre, academic writing

\section{Introduction}

Scholarly writing, editing, and publishing are global in their nature. The internationalisation of science has had a great impact on the ways new knowledge is produced and disseminated, with some outstanding national practices still preserved. Scholarly writing cannot help being understood within historical, social, cultural, and epistemological contexts (Sadeghi \& Alinasab, 2020).

Multilingual writers across the countries and disciplines operate in their national languages and often resort to English "to facilitate national scholarly exchange of ideas" (Salager-Meyer, 2014, p. 78). Scholarly sources that are considered high-ranking, mainstream, elite, top-tier, reputed, or centre scholarly sources are mainly produced in English (Salager-Meyer, 2014). As top-tier scholarly journals are essentially Anglophone, English second-language (L2) writers, or nonnative speakers (NNSs) (Flowerdew, 2001) across the globe are highly motivated "to communicate new knowledge in English" as their research will get better international visibility (Sheldon, 2011, p. 238). There are various motivational drivers that prompt researchers to get their manuscripts published in reputed English-language journals. The most cited reasons include collaboration or networking, the funding of research, promotion or tenure, and contributing to society (Lambovska \& Yordanov, 2020).

Historically, in some regions and countries, there were traditional genres of science writing, nation-specific perceptions of criticism, and academic disputes. The cultural load of writing implies a fundamental relationship between language and culture. The cultural aspects occasionally impede understanding or even erect some barriers to successful scholarly communication. 
Anglophone editors and referees outline various generic problems in L2 writers' submissions. In addition to surface errors, a lack of proficiency in scientific writing skills, unintelligible writing, weak analysis, incorrect or inadequate methodology, inconclusive results (Somashekhar, 2020), the absence of authorial voice, parochialism, nativized varieties of English (Flowerdew, 2001), less facility of expression (Flowerdew \& Wang, 2016), and occasional violations of ethics may occur.

Judging from our personal and professional experience and the surveys conducted among authors, reviewers, and editors, a number of issues were singled out that should not escape the attention of the wider scholarly community. We found, at least, seven issues closely connected to the cultural backgrounds of participants in the research-and-publishing process that editors and reviewers should be aware of.

\section{Unchecked Responses to Critical Feedback from Reviewers and Editors}

When reviewing submissions, difficulties, including misunderstandings, arise. Authors belonging to Eastern and non-Western cultures, i.e. cultures with high particularism, often tend to be more sensitive to criticism (Trompenaars \& Hampden-Turner, 1997). If such writers are well-established or prominent authorities on a subject area at national levels, they are not inclined to thoroughly revise their submissions, especially if criticism is related to structuring their manuscript or their bibliographic base with a bias towards national schools of thought, with leading international publications fundamentally ignored.

In some countries (e.g. high particularism is evidenced in Venezuela, Indonesia, China, South Korea, and countries from the former Soviet Union), criticism is rather formal and is put into subtle figures of speech, specific to the language and culture. In particularism-based cultures, some criticism may follow a long list of laudatory compensatory statements. When reviewing submissions, we often face quite aggressive responses to criticism that is untypical of cultures based on universalism, which focuses on rules (Trompenaars \& HampdenTurner, 1997).

Experience obtained by authors helps the process a great deal. They see how scholarly publishing operates in high-ranking journals and, finally, realize that in reviewing, it is not the criticism that matters but the quality of the submissions and final versions of the manuscripts.

\section{Different Understandings of Some Aspects of Science Ethics}

Ethics is not universal, despite the internalisation of science. Some national practices may differ from international norms. For example, in Eastern European countries and Russia, authors used to include texts of their published articles in monographs without any changes, as self-citation in such contexts was not considered unethical. In Israel, many researchers are in the habit of bringing out their previously published Hebrew-language articles in English, passing them off as original publications. The above examples are practice-related and need to be studied more broadly. With international practices coming to the fore, academics in the aforementioned countries are beginning to treat self-citation in the international mode. However, there are still practices in specific countries that may be in contrast with the internationally accepted ones.

National and international science editors and the greater publishing community must lead in spreading international norms of publishing ethics across disciplines and countries. Researchers at large should be informed of the changing ethical landscape. Experienced editors at international journals are certain to realize all the risks connected to submissions by non-core scholarly contributors.

\section{Prominence of Research: International vs National}

Citing local or internationally important sources and local or internationally prominent research themes are closely interrelated as the locality of research is usually linked to the national schools of thought. In the same sense, some authors (Anderson-Levitt, 2014) refer to the importance of research. Wide national differences exist in what is considered important or prominent. They are attached to topics central to a particular part of the globe (Anderson-Levitt, 2014). 
In submitted manuscripts from some countries, we see that references are overwhelmingly attributed to publications authored by their countrymen. Such a bias is typical of countries less open to internationalisation where academics have limited access to international sources and databases like Scopus and Web of Science. They often have no subscriptions to high-tier journals in their areas of research. Unfortunately, such submissions may be deficient in their relevance and prominence. If authors are not aware of the recent global developments in their field, their research becomes focused on themes interesting only for local or national scientists.

Some non-Anglophone writers are multilingual and can reposition "their literary-academic presences from their national contexts" to a global one and dilute their authors' voices among the core scientific community (Larson, 2018, p. 521). The core here refers to the core in the discursive system as opposed to the periphery and semi-periphery seen as a combination of three elements: linguistic, epistemological, and material (Larson, 2018).

The core in the discursive system operates through English and argumentation complied with Cartesian scientific rationalism. Second-language writers, able to completely align with the core, tend to succeed in publishing in top-tier journals, but their voices are blurred within their national scholarly community. Some of them are disengaged from national science, especially if invited to conduct studies and lecture at foreign universities (Harbord, 2018).

\section{Citing National Schools of Thought: Beating about the Bush?}

Non-Anglophone scholarly writers who turn to academic and literary brokers or translating services as well as L2 writers with a weak command of academic English are rarely aware of the recent publications in highranking English-language journals. There are at least two pieces of evidence proving the statement: references in periphery journals and the share of general citations in high-ranking journals. For instance, a citation analysis of the six leading journals on higher education attracted only 2.2 percent originating from non-OECD regions (Tight, 2014).

Second-language contributors like those mentioned above are not in the habit of regularly reading new articles. Thus, the bibliographic base of these researchers' submissions is often dominated by national or occasionally regional authors. It is sometimes surprising to find that the cited articles miss the most influential research on the topic, narrowed to unknown names of academics whose articles are second-tier for the field or far from being original. Moreover, sources and articles cited in such submissions are often not covered by popular databases, have no digital object identifier (doi), and are nearly invisible for international readers. In other words, such citations are dubious and earn no credibility.

Submissions from contributors of this kind are likely to be rejected. They often lack many essential components, including novelty and prominence, originality, a contribution to the academic field, as well as adequate style, rhetoric schemas, and format.

National schools of thought must share their progress with the wider scholarly community, but only within the contexts of regional and global science. National science cannot remain and develop in vacuum as if nobody had researched anything before.

\section{Mother-Tongue Based vs English-Language Patterns of Thought}

Language-related patterns of thought translate into the rhetorical structure of the text. Consequently, "secondlanguage researchers may be influenced by the rhetorical patterns of their native language" (Sheldon, 2011, p. 238). As those patterns in many languages are sometimes too far from the ones typical of English, native English editors and reviewers may misunderstand the message or become irritated by too detailed or superfluous information.

Fluent L2 writers tend to mimic lots of native English-language patterns in their writing, with their native language patterns interfering less as compared with novice second-language authors. The former still may 
prefer submitting their manuscripts to international journals where global English is a norm, with nonAnglophone editors. The statement may be found quite disputable and needs further studying.

\section{Nation-Specific Understanding of Genres of Scholarly Writing}

Genres of written scholarly communication across the globe are becoming uniform. Genres are indissociable from social and procedural knowledge (Ketabi \& Rahavard, 2013). Therefore, there are historical and cultural differences in understanding what each genre implies. Genres are aligned with patterns of thought, moves and steps, and lexical bundles. They may also be more or less preferred in particular disciplines. It can be challenging for L2 writers to realize that the same-named genres in their native language may have not much in common with the corresponding genres in English.

\section{English Texts Produced by Native Speakers and L2 Writers: Rhetoric Moves and Steps}

Proficient L2 scholarly writers may succeed in going along with English-language rhetoric schemas in their texts. However, mother-tongue interference occasionally distorts the rhetorical structure and, thus, is likely to lead to misunderstandings or a poor perception of the scholarly message. Academics, especially young and new-career, often let their L1 or native language influence rhetorical moves and steps in their English writing. Learning to naturally express thought according to rhetoric patterns of a language is the mastery level of fluency (Alamri, 2020).

The problem lies in very specific language-related patterns of thought. If English patterns are straightforward and close to formal logic, other languages are prone to zigzagging, either parallel or non-parallel, digression or going off the point (Kaplan, 1966). One more stigma of other language rhetoric is the scope of detailing and background. Some languages allow more backdrop information, or loosely associated sidelines of the story being told. For Anglophone editors or reviewers, such texts abound in excessive information or are overloaded and cumbersome to understand.

Submissions in humanities and social sciences written in English in accordance with such foreign schemas are often desk-rejected. Writings in sciences tend to become a little less important as key information is transmitted via formulas. Wording becomes second-tier and less meaningful. This kind of barrier may remain in place for a long time if academic writing and scholarly communication skills in English are not thoroughly compared to native-language patterns of thought. The language and culture of a specific country cannot help being considered in the approaches to teaching and learning scholarly communication in English (Voevoda, 2020).

Cultural differences will remain in place for many years to come. They may enrich science publishing by including an international perspective, cross-linguistic and cross-cultural issues, and objectivity of outside perspectives (Flowerdew, 2011). Editors and reviewers ought to factor them into their work. Second-language writers must learn about their impact while taking courses in academic English and writing for scholarly publication. L2 researchers' willingness to improve their skills relating to the culture-related components of writing is the key to progress (Raitskaya \& Tikhonova, 2020).

\section{Conclusion}

There are a number of observations and recommendations that may be helpful for overcoming these hurdles.

First, one way to mitigate aggressive responses to reviewers' and editors' critical feedback is to describe all the requirements in detail, adding a kind of mildly worded recommendation instead of blunt statements regarding the deficiencies or faults in submissions.

Second, in order to internationalise national science, the academic community has to continuously review research ethics to fully meet the global norms. National associations of editors and publishers, as well as learned societies and universities ought to lead the social reinvention of ethical behaviour patterns, especially 
breeches of ethics. The wider academic community needs to be involved to change the conflicting attitudes on misconduct in scholarly publishing.

Third, scholarly writers in periphery and semi-periphery countries are in need of a helping hand to get their bearings in areas of research on a global scale. Scientometrics centres or experts may be of assistance in refining the prominence of research conducted by periphery academics. Some national programmes can provide wider access to international databases and electronic libraries.

Fourth, concerted efforts of educators, journals and authors in periphery and semi-periphery countries could lead to a better comprehension of the field of study and directions for research on a global scale. It is essential for authors to actively rely on a wider bibliographic base. They must realize what their field of research is like globally and in comparison with national science. Unlimited access to international databases is also a prerequisite. That being said, it is simply not the opportunity, but the willingness to be kept abreast of recent internationally important contributions to the field that substantially matters. We believe that the greatest challenge is crossing the traditional boundaries of the field often limited to national or even institutional schools of thought as they develop more or less isolated from global science.

Fifth, patterns of thought in a foreign language often interfere with native patterns. Studying academic writing and writing for publishing skills can help improve the way second-language authors express their thoughts. Language brokers and native English proofreaders can efficiently raise the readability of scholarly writing.

Sixth, L2 authors study genres and the corresponding discourse both within academic English courses and when practising writing on their own. Reading the best samples of genres may be very useful.

Seventh, by knowing and following moves and steps in every piece of writing, L2 researchers are sure to succeed.

Practice makes perfect. Gaining experience takes years and many failed and successful submissions to reputed journals. Joint efforts among all the parties concerned will help writers overcome many of the hurdles and lead to positive outcomes.

\section{Conflict of interests}

The authors declare that they have no conflict of interest.

\section{References}

Alamri, B. (2020). A comparative study of Saudi and international journals of Applied Linguistics: The movebundle connection approach. Journal of Language and Education, 6(2), 9-30. https://doi.org/10.17323/ jle.2020.10531

Anderson-Levitt, K. M. (2014). Significance: Recognizing the value of research across national and linguistic boundaries. Asia Pacific Education Review, 15(3), 347-354. https://doi.org/10.1007/s12564-014-9322-0

Flowerdew, J. (2001). Attitudes of journal editors to non-native speaker contributions. TESOL Quarterly, 35(1), 121-50.

Flowerdew, J. \& Wang, S. H. (2016). Author's editor revisions to manuscripts published in international journals. Journal of Second Language Writing, 32, 39-52. https://doi.org/10.1016/j.jslw.2016.03.004

Harbord, J. (2018). Language policy and the disengagement of the international academic elite. Science Editing, 5(1), 32-38. https://doi.org/10.6087/kcse.115

Kaplan, R. (1966). Cultural thought patterns in intercultural education. Language Learning, 16, 1-20. https://doi. org/10.1111/j.1467-1770.1966.tb00804.x

Ketabi, S., \& Rahavard, S. (2013). Cultural variations across academic genres: A generic analysis of intertextuality in master's theses introductions. English Language Teaching, 6(11), 148-159. https://doi.org/10.5539/elt. v6n11p148 
Lambovska, M., \& Yordanov, K. (2020). Motivation of researchers to publish in high-quality journals: A theoretical framework. TEM Journal, 9(1), 188-197. https://doi.org/10.18421/TEM91-27

Larson, J. (2018). Other voices: authors' literary-academic presence and publication in the discursive world system. Discourse: Studies in the Cultural Politics of Education, 34(4), 521-535. https://doi.org/10.1080/01596 306.2016.1278357

Raitskaya, L., \& Tikhonova, E. (2020). Overcoming cultural barriers to scholarly communication in international peer-reviewed journals. Journal of Language and Education, 6(2), 4-8. https://doi.org/10.17323/jle.2020.11043

Sadeghi, K., \& Alinasab, M. (2020). Academic conflict in Applied Linguistics research article discussions: The case of native and non-native writers. English for Specific Purposes, 59, 17-28. https://doi.org/10.1016/j. esp.2020.03.001

Salager-Meyer, F. (2014). Writing and publishing in peripheral scholarly journals: How to enhance the global influence of multilingual scholars? Journal of English for Academic Purposes, 13, 78-82. https://dx.doi. org/10.1016/j.jeap.2013.11.003

Sheldon, E. (2011). Rhetorical differences in RA introductions written by English L1 and L2 and Castilian Spanish L1 writers. Journal of English for Academic Purposes, 10, 238-251. https://doi.org/10.1016/j.jeap.2011.08.004

Somashekhar, S. P. (2020). Art of scientific writing. Indian Journal of Gynaecologic Oncology, 18(2). https://doi. org/10.1007/s40944-020-00382-y

Tight, M. (2014). Working in separate silos? What citation patterns reveal about higher education research internationally. Higher Education, 68(3), 379-395. https://doi.org/10.1007/s10734-014-9718-0

Trompenaars, F., \& Hampden-Turner, C. (1997). Riding the waves of culture. Understanding the cultural diversity in Business. Nicholas Brealey Publishing.

Voevoda, E. (2020). Intercultural communication in multicultural education space. Training, Language and Culture, 4(2), 11-20. https://doi.org/10.22363/2521-442X-2020-4-2-11-20 